\title{
The Structural Analysis of Indonesian Horror Webtoon's Visual and Narrative
}

\author{
Basyarayni Mawla Fatha ${ }^{1, *}$, Alvanov Zpalanzani Mansoor ${ }^{2}$ \\ ${ }^{1}$ Institut Teknologi Bandung, Indonesia \\ ${ }^{2}$ Institut Teknologi Bandung, Indonesia \\ *Corresponding author. Email:mawla.fatha@gmail.com
}

\begin{abstract}
The popularity and the appeal of horror media among Indonesian have been explicated as a close relation to the psyche of Indonesians which is generally inherent to the Eastern culture. This specific pattern of preferences rooted in Indonesians' cultural fixation has been profited off across many forms of popular media; from radio broadcasts to online podcasts, from TV series to cinematic movies, and from printed comics to webtoons. Webtoon or webcomic is a term originally coined in Korea to refer to a form of graphic narrative that interweaves words and images as also found in printed comic, however, its utilization of digital information technologies implies a fundamental difference between the two. Webtoon's vertical orientation is also one of the few discrete factors that excludes webtoon from the printed comic category. This research aims to find out how the visual narrative structures of Indonesian horror webtoon are particularly employed in evoking fear within the readers' minds by examining some representative examples of popular Indonesian horror webtoon: Creep by Ino Septian and Gloomy Sunday by Fanky Landerson. This analysis is conducted by applying Zpalanzani-Tabrani and Cohn's triangulation analysis model enhanced by adding the structural affect theory of stories developed by Brewer and Lichtenstein and some supplemental analysis units such as gutter space and colour analyses. This study suggests that there are some idiomatic similarities between Indonesian horror webtoons and horror films in general, both in terms of visual composition and units and in terms of sequence to construct a sense of suspense in an engaging and ceaseless horror experience. These findings are applicable to obtain an effective formulation in designing horror webtoon for Indonesian readers on one hand, and to draw out some encouraging remarks for further improvement on some aspects on the other hand.
\end{abstract}

Keywords: Graphic storytelling, horror, visual narrative, webtoon, webcomic

\section{INTRODUCTION}

Ahmad, et al. reveals that thoughts, views, and visual realities occurring in one place and the time or era people aim to represent can be revealed through comics within a cultural context [1]. Therefore, the notion of certain genres or sub themes becoming more popular in one area compared to the others is likely to be expected. As one of the popular culture products that reflects the specific cultural values, beliefs, and thoughts Indonesian people hold, readers' preferences in certain sub themes of fictional works can also be evaluated in webtoon or webcomic.
As quoted by Nurgiyantoro [2], Wellek and Warren defined the extrinsic elements of a fictional story as the condition of the author's subjectivity interconnected with attitudes, beliefs, and views of life, all of which influence the works created by the author in some type of way [3]. Even so, these components are not associated with decisions that randomly emerge in the subconscious state of the author's mind only; the author's psychological being, readers' preferences, and the circumstances surrounding the author's intangible environment (economic state, political state, and social environment) also have an impact that exerts an influence on the works the author created. 
There is a certain tendency of Indonesian horror webtoon readers regarding their preference towards some specific horror sub themes; Indonesian readers happened to be more drawn to the kind of horror that represents the local myths and beliefs within the narrative which also portray mythical creatures believed by the locals [4]. Fear is a conditional thing, apart from being related to the external stimuli such as images and audio, fear is also triggered by the cognitive scheme in the mind particularly derived from one's cultural background and the ideals held by a community or a group. This creates some cultural references within the horror dimension itself that will only be understood and appreciated to a greater extent by people who hold the same cultural values and beliefs.

This notion is increasingly evident with numerical data showing that the local myths sub theme is a common horror theme that reoccurs among the top 3 of Indonesian horror webtoons in the chart. As of February 2021, Ino Septian's Creep (LINE webtoon, 2016) has attracted more than 1 million followers with an average number of engagement points in each episode of more than 38,298 likes, 10 PM (Arvidan, 2019) has attracted more than 369,000 readers with an average engagement number in each episode of more than 35,417 , these two webtoon titles applied similar themes and visualization techniques through jump scare in several episodes. These numbers contrast with how other horror webtoons that applied a different approach got lesser engagement points as seen in Sing Bahu Rekso (Robbi, 2017) with an average engagement point of 12,211 approximately in each episode, or Curse of Tomorrow (Prayoga, 2019) with an average engagement point a total of 11,498 points per episode. Sing Bahu Rekso carries the natural horror theme by conveying the horror experience within its narrative through mutant crocodiles, whereas Curse of Tomorrow carries a discrete set of sub theme with zombies, cops' investigation, and curses.

As a medium that utilizes the major characteristic of digital technologies through internet networks [5], webtoon has an entirely different structure compared to the printed medium, even though webtoon itself is still classified as sequential art [6]. This study aims to analyse how the visual narrative structure of
Indonesian horror webtoon evokes fears within the readers' minds and draws them into a dimension of an engaging horror.

In order to provide reasonable explanations, this research is focused on using pieces of literature as its main source of justifiable argumentations. The object of study for this research is represented by three Indonesian horror webtoons taken from two series that were selected based on a specific pattern of readers' preferences in Indonesian horror webtoon through a pre-liminary research. These three selected objects applied different narrative and visual approaches to one another to avoid any bias occurring in the results. The Zpalanzani-Tabrani and Cohn triangulation analysis model is applied as an analytical methodology to determine the intangible aspects of the narrative, the tangible aspects of the visualization, and the sequential aspects related to the sequence of events and the arrangement of scenes in the panels to form a unified narrative. Several units of analysis such as the analysis of gutter space, the analysis of colours, and the affective responses that arise from the discourse structure are also added to the triangulation analysis model to adjust the methodology with the object of research considering the unique structure of the webtoon itself. The Zpalanzani-Tabrani and Cohn triangulation analysis model is a further development of the Zpalanzani triangulation analysis model that was initially used to analyse the visual narrative structure of Indonesian girl's comics.

\section{METHODS}

Zpalanzani argues that a piece of graphic narrative work is built upon three main components: the intangible aspect, the tangible aspect, and the sequential aspect [7]. These three components are further broken down into several independent units which are interrelating with one another to form a coherent structure within each unit. This analysis model was initially used to examine the visual narrative structure of Indonesian girl's comics, however, the adaptability this analysis model offers can also be utilized for any development onward depending on what category the object of study falls into, either by adding new analysis units or eliminating some of the already existing subdivisions. 


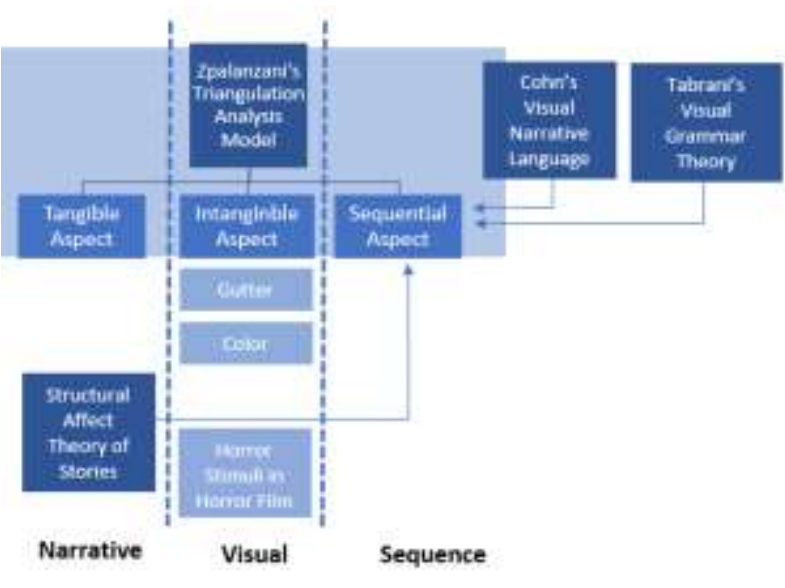

Figure 1 revamped analysis model

Some new analysis units such as webtoon's onomatopoeia typography, gutter space, and colours are added to enhance the previously established analysis model. These units are included in the tangible aspect category. The gutter space analysis unit is added considering its differentiation both on webtoon and conventional printed comics at a significant level. Regardless of this, many comic scholars have also argued that reader's active participation transpires in the gutter area itself, this remark includes both printed comics and webtoons in its principle; how wide or narrow the gutter area either of them has is of no importance. The gutter space that connects each panel lets the readers construct and generate meanings from an assemblage of still images where they fill the space in line with their own interpretations. This unique purpose of the gutter space, however, takes a passive role in printed comic due to its page size limitation, whereas the disenthralling size of webtoon's canvas height allows the creator in utilizing the gutter space to its maximum potential to contribute to the narrative in various ways: to create a sense of duration, to create a diversified visual space that complements the text, and to express a set of mood and tone to the story depicted within the panels [8].

Another supplementary unit is added to the sequential aspect category; the structural affect theory of stories developed by Brewer and Lichtenstein deals with how a discourse structure elicits a certain affective response within the reader's mind as a result of a manipulation of the narrative structure in the story. There are three predominant categories of the affective responses that arise out of such structural manipulation: surprise, suspense, and curiosity.

Noël Carroll considers suspense as a necessary ingredient of every horror story; he argues that the predictability of the storylines in horror narrative requires certain narrative techniques in keeping the readers' interest by evoking some emotional experience [9]. According to Hoeken and van Vliet, suspense is aroused by eliminating the outcome or the impact of the story from discourse structure thus eliciting a sense of uncertainty [10].

The first object of study is one of Ino Septian's works from Creep webtoon series titled Mati! (Die!), this episode depicts a story of a father of three who resurrects from his death and finds himself already being interred deep under the ground after he dreamt of reuniting with his children, he tries to escape from his grave but to no avail. This episode is chosen following the writer's testimony that considers the eleventh episode of Creep to be the most spinechilling story he ever created [11]. The second object of study is taken from the same series with entirely different visual and narrative approaches compared to the first object of study, Merah Miyah! (Red Miyah!) is the sixth episode of Creep webtoon series that represents the general audiences' preferred theme regarding local myths. The last object of study comes from Gloomy Sunday webtoon series created by Fanky Landerson, one story arc from the sixteenth to the seventeenth episode is appraised as an archetypal theme in the webtoon series itself with dark fantasy theme and body horror.

\section{RESULTS}

This analysis suggests that there are idiomatic similarities between Indonesian horror webtoons and horror films, both in terms of visual composition and visual units, and in terms of sequences in building the horror. This similarity occurs due to some restraint in screen size both media provide (TV screen, movie theatre projection screen, or phone screen). Nonetheless, horror webtoons and horror films utilize different kinds of screen orientation contrasting to one another. This further affects the experience felt when reading horror webtoon shown on whichever kind of screen orientation they are being displayed on; reading horror webtoon on a computer screen will not exceed the experience felt to reading horror webtoon shown on a phone screen. One panel in a webtoon a phone screen can display is equal to half or even a third of the panel shown on a computer screen. 


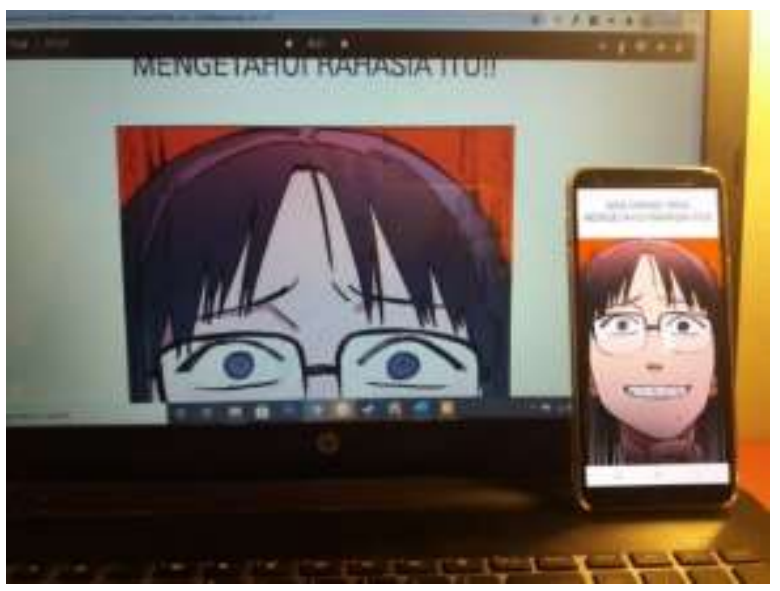

Figure 2 Size aspect ratios of PC screen and phone screen comparison

These idiomatic similarities are indicated through visual composition within the panel which draws the reader's attention to one vanishing point before abruptly changing the event with a startling jump scare. For instance, the 6th episode of Creep shows a scene where Nara -one of the characters in the storypoints his finger at a dark space at the corner of his house before the light bulb on the ceiling suddenly flickers and surprises the readers. Regardless of nothing frightening popping out from the dark corner, it still effectively scared the readers through a well-composed visual that evokes uncertainty and suspense.

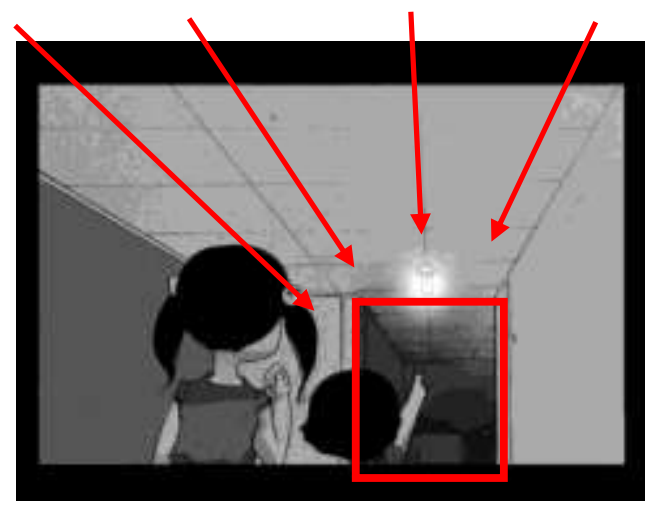

Figure 3 The visual composition as a prelude to horror

Another aspect that demonstrates the similarity between the two is implied through "alih slow motion" interspacing the panels. Keep in mind that the gutter space takes a pivotal part as one of webtoon's visual components, the more spacious the gutter area is the longer the time has passed. "Alih slow motion" is also a commonly used technique found in most horror films to trigger suspense. Primadi defines "alih slow motion" or slow-motion transition in his visual language principle as a branch category of "tata ungkap luar" that emphasizes motion, time and space, and importance by a decelerated duration of the scene depicted [12].

In printed horror comics, arisen suspense and anticipation from a slowing pace of an event are steadily accumulated within the reader's minds through a certain type of panel transition; moment to moment and aspect to aspect transitions are commonly used by horror comic artists to escalate the feeling of uncertainty. This panel transition type is demonstrated by panels belonged to the prolongation category in Cohn's visual narrative grammar principle [13]. This visual transition technique utilized in printed comics is amplified by manipulating the size of the gutter area thus constructing an even slower pace and a more intense built-up suspense in horror webtoon.

Despite their idiomatic similarities, however, passive participation provided by the audiences is the only condition horror films require, the audiences do not take any control with everything occurring behind the scenes in a technical sense by any means. Meanwhile, some horror webtoons that do not require moving images (GIF) to enhance fears experienced by the readers encourage active participation from the readers themselves, they have the capability of controlling the pace of the story shown on their phone screen only with a flick of their thumb. Some other kind of webtoon that utilizes moving images (GIF) draw out semi-passive participation from the readers. This puts webtoon in the middle points of the spectrum based on requisite readers' participation.

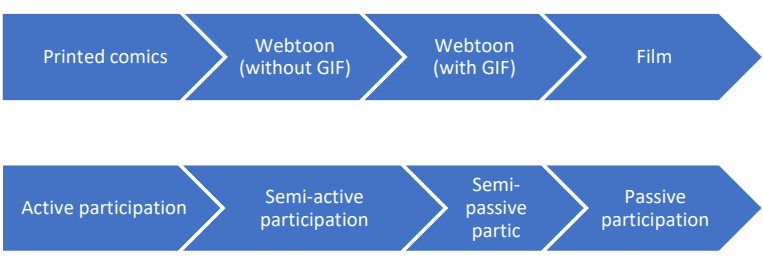

Figure 4 The spectrum of three types of visual horror media and their relationship to the readers' participation.

Aside from being utilized in forming a certain length of duration, creating a particular sense of pace of the events that are meant to provoke suspiciousness makes use of the spacious gutter space, although not being one of the climax scenes or 
jump scare itself. As we can see in one of the examples provided when Nara (6th episode of Creep) points his index finger at Nilam's room's door, or when Arin (16th episode of Gloomy Sunday) arrives on the scene and witnesses the wall in a dead-end alley already being covered with missing person posters smeared in blood. Prior and after the panels depicting the two scenes are shown, there is a fairly large gap in the gutter area interspacing the panels, various expectations begin to emerge in the readers' minds thus evoking wariness from the spacing of the gutter area alone; will something frightening appear after this or not? The wide gutter space between panels locks the reader's sight on one particular panel only, the reader cannot see the next panel before they scroll down further.
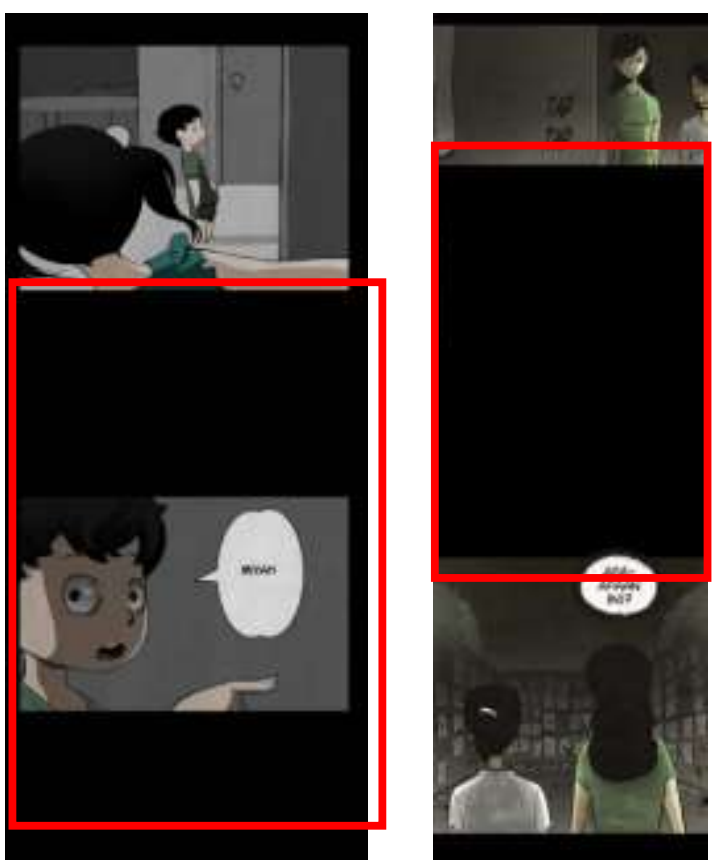

Figure 5 Gutter spacing in scenes requiring suspension.

The horizontal orientation of a computer screen is not compatible with the vertical orientation of a webtoon, this then creates white blank spaces on the left and right sides sandwiching the webtoon shown on a computer screen. This will interfere with the readers' attention to the object portrayed in the panel, white light contains the three primary colours (RGB) resulting in high frequency from combined various wavelengths [14], in other words, the intense brightness of white space framing the webtoon can be distracting to the eyes. The high brightness quality of white light reduces the effectiveness of the horror delivery.
This also explains horror webtoon creators' tendency to fill the gutter area with plain black colour. In addition to amplifying the horror atmosphere by putting an emphasis on darkness through the colour of the gutter space, the pitch-black gutter area also reduces the capacity of light penetrating the eyes, this keeps maintaining the readers' attention towards the panels rather than the gutter area itself. This notion is further reinforced with the fact that webtoon can only display a limited amount of panel grouping in each scrolling section which limits and locks the reader's navigation even more. They will not be able to deliberately skip each panel, in contrast to printed comics where they can skim through the pages to get to a specific scene.

Combining the desaturated colour palette with pitch-black is also a recurring visual technique used by the creators to intensely arouse the sense of perturbation of something they cannot visually sense. The low brightness quality of black colour limits the viewer's vision or attention of the surrounding environment in the webtoon they perceive. This limited knowledge and sensory perception that the observer has of the surrounding environment fosters the fear of dark surroundings [15].

The portrayal of pale-skinned characters with skinny -almost skeletal- body proportion is a common visual technique applied by the creators to escalate the horror experience as well. The frail body proportions, pale skins, and gloomy faces are a few visual qualities and cues associated with the state of unwell mental and physical beings. Characters who are often expressed with a dreary look on their faces throughout the story will take the readers into a spiralling down emotional aftermath. The prolonged negative emotions the readers feel through the story further affect the reader's perception and impression of the horror experience presented like a snowball effect [16].

Without regard to specific details or exceptions, the three objects of research can be divided into three categories of horror based on how the horror experience is brought to the readers:

1. Horror that is formed through explicit visualization,

2. Horror that arises from anticipation as a prelude to horror, and

\section{Horror that emerges through empathy.}

The first and second types of horror are related to the outermost layer of human fear perception through their visual sensory. They frighten the readers through some explicit and striking visualizations by 
either one of the three visual horror stimuli or the combination of the three: 1. Prevalence of dangers and injuries, 2. Distortions of natural forms, and 3. Arousal-enhancing stylistic techniques [17]. Fear is not evoked by the visual impact, or the aftereffect of the horror shown in a subtle or symbolical manner, rather, it is triggered by exposing the readers directly to the explicit visual stimuli.

Demonstrating the dialectically moulded violent scenes by not explicitly showing the horror is arguably possible to achieve. This might sound like an oxymoron, but it is considered a common practice in Japanese theatrical to represent an explicit scene by showing the impact of the circumstances that occur after the said scene instead of showing the process itself. For instance, a wall streaked and covered in splashes of blood indicates a slaughter that happened not long ago in the room, it does not illustrate the process of the murder in veritably tangible details, yet the audiences can still get the gist of a recently occurring murder by the visual cues alone [18].

Direct exposure to visual stimuli has become a recurrent theme frequently found in Indonesian horror webtoon. The horror is not perceived through a second-hand experience contagiously shown on the characters' dreaded expressions. This is known as social fear transmission in psychology. Various studies denote that the exposure to certain social hints alerting threats such as the sight, sound, or smell of a scared conspecific may potentiate vicarious fear response [19]. Indonesian horror webtoons' visual format still revolves around the first-hand fear reaction experienced by the readers due to the creators' agitation to deliver the shock visual factor in a graphic fashion.

The third category of horror in Indonesian horror webtoon is inherently different from the other two as represented by the 11th episode of Creep. Although it still has its repulsive moment where a human corpse slides into Nilam's father's graveyard pit, leaving him petrified beside the rotting corpse, it does not necessarily utilize the appalling and startling visual stimuli compared to the others. The 11th episode of the Creep series focuses on the subjective experiences conveyed to the readers from Nilam's father's point of view through the depiction of dead bodies wrapped in shrouds. This approach can be categorized as abjection. Simply put, abjection refers to the human response of being confronted with the sort of traumatic materiality, this specific reaction emerges due to a threatened breakdown in meaning caused by the loss of the distinction between subject and object or between self and other [20]. Kristeva associates such response with human's rejection of death's insistent materiality, death devastatingly reminds humans of their mortality as a negation of their material existence. The depiction of a corpse or cadaver is one of few triggering instances for an abject to erupt.

Some events depicted within the panels take a 1:1 or 1:2 ratio to classify the climactic event of the horror itself. Nevertheless, this certainly cannot be a fixed determinant of the climax scene of the horror considering how some establishing panels also have the same size ratio. A sense of longer duration formed between one panel to another is the only distinguishing indicator that particularly demonstrates a climactic scene of the horror, it often acts jointly with the slow pace formed from a wider interlude of the gutter area between the panels.

\section{DISCUSSION AND CONCLUSION}

In terms of narrative construction, popular Indonesian webtoons tend to adopt some cultural references as a basis of the horror narrative, both the urban myths and the old tell-tales. These cultural references stemmed from Indonesians' cultural fixation are not related to mythical beings only, instead, in a more general sense, broader and more general fear stimuli also come in handy to coordinatively evoke fears such as death and phobias. Whereas in terms of visual construction, a close relatability the readers can engage themselves in is achieved by creating an environment built upon attributes they encounter daily into the horror environment. For instance, the typical settings of a place recognized by the general audience of Indonesian readers (such as the style of residential buildings in Indonesia, burial areas, small alleys, schools, etc.) are integrated to create a sense of relatability to draw the readers' subjective participation within the horror dimension. The distinct physical features of Indonesians are commonly found on the characters as well with their black iris and black hair.

The limited screen width webcomic format has to offer creates some idiomatic visual similarities between horror webtoons and horror films; from its visual components to the way the horror is delivered. Gutter space takes a pivotal role in significantly amplifying the suspense due to its ability to create a longer duration span printed comics can never achieve. 
In a general scope, suspense is built upon a decelerating pace regardless of which form of media it takes. In printed comics, this is preferably demonstrated through an assemblage of images that focuses on smaller moments rather than the keyframes of the event themselves. Illustrating the quality of the scene is achieved by detailly putting the framed event on brakes thus producing a slower pace that suspiciously intrigues the readers. Cohn refers to these panels as prolongation, they do not provide any new informative details to the sequence, rather, it usually functions just to delay the climactic event [21]. In webtoon, this is improved by separating the prolongation panels by wider gutter area. Webtoon's use of colours also reinforces the notion of webtoon's and film's idiomatic similarities even further. Desaturated colour and pitch-black colour combination, which is frequently found in horror films [22], can also be found in most Indonesian horror webtoons.

\section{ACKNOWLEDGEMENT}

This research is funded by Industrial Mapping and Representation of Indonesia in Contemporary Indonesia's Comic 2008 - 2018 from P3MI Program ITB fiscal year 2018.

\section{REFERENCES}

[1] H. Ahmad, B. Maulana, A. Zpalanzani. Histeria! Komikita. Elex Media Komputindo, Jakarta, 2006.

[2] B. Nurgiyantoro. Theory of Fiction. Gadjah Mada University Press, Yogyakarta, 2000.

[3] R. Wellek, A. Warren. Theory of Literature. Harcourt, Brace \& World, Inc., New York, 1956.

[4] B.M. Fatha, A.Z.Mansoor. An Analysis of Indonesian Horror Webtoon's Characteristic on LINE Webtoon (2016 - 2020). DESKOMVIS: Jurnal Ilmiah Desain Komunikasi Visual, Seni Rupa, dan Media, Volume 1(3), 2020, pp. 184200.

[5] D.Y. Jin. Digital Convergence of Korea's Webtoons: Transmedia Storytelling. Communication Research and Practice, Volume 1(3), 2015, pp. 193-209.

[6] S. McCluod. Reinventing Comics: How Imagination and Technology are Revolutionizing an Art Form. Perennial, New York, 2010.
[7] A. Zpalanzani. Girls Representation in Indonesian Girls' Comics of the 2000s [Dissertation]. Institut Teknologi Bandung, Bandung, 2012.

[8] H. Cho. The Webtoon: A New Form for Graphic Narrative [Internet], 2016, http://www.tcj.com/the-webtoon-a-new-formfor-graphic-narrative/ Available from: The Comic Journal.

[9] N. Carroll. The Philosophy of Horror: Or, Paradoxes of the Heart. Routledge, London, 1990.

[10] H. Hoeken, M. van Vliet. Suspense, Curiosity, and Surprise, How Discourse Structure Influences the Affective and Cognitive Processing of a Story. Poetics, Volume 27, 2000, pp. 277-286.

[11] A. Indri. A Guide to Creep [Internet], 2018, https://summerballads.wordpress.com/2018/04/2 9/panduan-membaca-Creep/ Available from: Wordpress.

[12] P. Tabrani. Visual Language. Kelir, Bandung, 2012.

[13] N. Cohn. Visual Narrative Structure. Cognitive Science, Volume 37(3), 2013, pp. 413-452.

[14] D.H. Sliney. What is Light? The Visible Spectrum and Beyond. Eye, Volume 30(2), 2016, pp. 222-229.

[15] J. Levos, T.L. Zacchill. Nyctophobia: From Imagined to Realistic Fears of the Dark. Psi Chi Journal of Psychological Research, Volume 20(2), 2015, pp. 102-110.

[16] D.M. Sari. An Analysis of Visual Storytelling Structure of Junji Ito's Horror Comic [Thesis]. Institut Teknologi Bandung, Bandung, 2020.

[17] J. Cantor, M.B. Oliver. Developmental Differences in Responses to Horror. In: J.B. Weaver (III), R. Tamborini, editors. Horror Films: Current Research on Audience Preferences and Reactions. Lawrence Erlbaum Associates Inc., New Jersey, 1996.

[18] Z. Serper. The Bloodied Sacred Pine Tree: A Dialectical Depiction of Death in Kurosawa's Throne of Blood and Ran. Journal of Film and Video, Volume 52(2), 2000, pp. 13-27.

[19] J. Debiec, A. Olsson. Social Fear Learning: from Animal Models to Human Function. Trends in Cognitive Sciences, Volume 21(7), 2017, pp. 546-555. 
[20] J. Kristeva. Powers of Horror: An Essay on Abjection. L.S. Roudiez, translator. Columbia UP, New York, 1982.

[21] N. Cohn. How to Analyze Visual Narratives: A Tutorial in Visual Narrative Grammar [Internet], 2015 ,

http://www.visuallanguagelab.com/P/VNG_Tut orial.pdf Available from: Visual Language Lab.

[22] I.P. Chen, F.Y. Wu, dan C.H. Lin. Characteristic Color Use in Different Film Genres. Empirical Studies of The Arts, Volume 30(1), 2012, pp. $39-57$. 